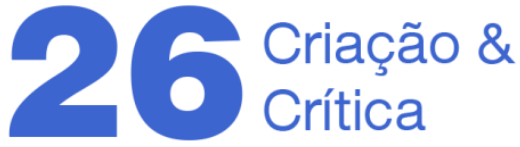

\section{A TEORIA DESENVOLVIMENTISTA DO “SUPER-REGIONALISMO" EM Antonio Candido e o caso ARguedas}

Gabriel dos Santos Lima ${ }^{1}$

RESUMO: O presente artigo se propõe a repensar a categoria literária de "super-regionalismo", elaborada por Antonio Candido em seu ensaio "Literatura e Subdesenvolvimento" (1970). Para isso, em primeiro lugar, recordaremos a linha argumentativa de tal texto, segundo a qual as obras de escritores latino-americanos dos anos 1960 - notadamente Augusto Roa Bastos, Gabriel García Márquez, João Guimarães Rosa e José María Arguedas - representariam pontos de síntese entre matéria regional e técnicas artísticas modernistas, constituindo uma literatura universalmente significativa. Em seguida, buscaremos demonstrar como esse projeto de modernização literária "super-regionalista" se associava, na obra candidiana, à ideologia desenvolvimentista da década de 1960 e a determinadas expectativas em relação aos rumos da revolução cubana. Por fim, sugeriremos repensar o conceito de "super-regionalismo" à luz do processo histórico dos anos 1970 em diante, que se caracterizou, em toda a América Latina, por um desenvolvimento capitalista concomitante ao massacre das esquerdas, ao aumento da desigualdade social e ao extermínio de culturas locais. Para tal, consideraremos também aspectos da obra Los Ríos Profundos (1958) de Arguedas, que já na década de 1950 parece assinalar tensões em relação à leitura sugerida por "Literatura e Subdesenvolvimento", antecipando problemas que ficariam mais claros nos anos seguintes.

PalaVRAS-Chave: Antonio Candido, José María Arguedas, Literatura e Subdesenvolvimento, Literatura Latino-Americana.

\section{ANTONIO CANDIDO'S DEVELOPMENTALIST THEORY OF “SUPER-REGIONALISM” AND THE ARGUEDAS CASE}

ABSTRACT: The current paper aims to rethink the literary category of "super-regionalism", elaborated by Antonio Candido in his essay "Literature and Underdevelopment" (1970). For this, firstly, we will remember the argumentative line of such text, according to which the works of Latin American writers of the 1960s - notably Augusto Roa Bastos, Gabriel García Márquez, João Guimarães Rosa and José María Arguedas - would represent points of synthesis between regional matter and modernist artistic techniques, constituting a universally significant literature. Next, we will try to demonstrate how this project of "super-regionalist" literary modernization was associated, in the Candido's work, with the development ideology of the 1960s and with certain expectations regarding the outcomes of the Cuban revolution. Finally, we will suggest rethinking the concept of "super-regionalism" in the light of the Latin-American historical process from the 1970s onwards, which was characterized by a capitalist development concomitant with the massacre of the left, the increase of social inequality and the extermination of local cultures. To this end, we will also consider aspects of Arguedas's Los Ríos Profundos (1958), which already in the 1950s seems to

\footnotetext{
${ }^{1}$ Mestre em Letras pela Universidade de São Paulo e doutorando no Departamento de Teoria Literária e Literatura Comparada da mesma universidade, com estágio de doutorado na Yale University (EUA). E-mail: gabriel.cordeiro.lima@usp.br .
} 


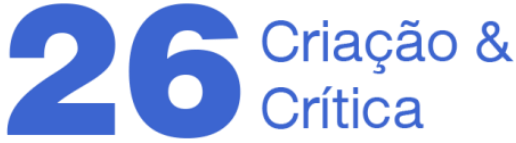

point out tensions in relation to the reading suggested by "Literature and Underdevelopment", anticipating problems that would become clearer in the following years.

KeYwords: Antonio Candido, José María Arguedas, Literature and Underdevelopment, LatinAmerican Literature.

\section{Introdução}

O ensaio "Literatura e Subdesenvolvimento" foi escrito em finais dos anos 1960 por Antonio Candido a pedido do intelectual uruguaio Ángel Rama, com quem o crítico brasileiro desenvolvera sólida relação de amizade e interlocução. Em 1970, o texto sairia na revista Cahiers d'Histoire Mondiale, da UNESCO, com tradução para o francês de Claude Fell ${ }^{2}$. No mesmo ano, sua tradução para o espanhol se somaria à obra coletiva América Latina en su Literatura e, em 1973, seria dada a conhecer sua primeira edição em português no número 1 da revista Argumento.

Desde então, "Literatura e Subdesenvolvimento" serve de referência a inúmeros trabalhos acadêmicos, compondo a bibliografia de muitas disciplinas universitárias. Sua influência se deve, entre outros atributos, à cuidadosa sistematização das tensões artísticas e ideológicas que preocupavam a crítica literária latino-americana nos anos 1960. Desses problemas, como observou Roberto Schwarz, o texto constitui um "balanço magistral" (SCHWARZ, 2018, p. 74).

Algumas de suas categorias, entretanto, parecem hoje excessivamente tributárias do contexto histórico e político dentro do qual Candido as formulou. Tal é, particularmente, o caso do conceito de "super-regionalismo" (CANDIDO, 2011b, p. 195), aplicado pelo crítico a uma série de romances da época que, a seu ver, conciliavam a matéria regional da América Latina às técnicas narrativas do romance modernista europeu. Como buscaremos demonstrar, essa noção sugeria um processo de modernização literária; por sua vez, historicamente atrelado à ideologia desenvolvimentista dos anos 1960, a qual ambicionava um desfecho progressista das lutas políticas de então. Todavia, considerado o processo histórico dos anos 1970 em diante - marcado pela destruição de culturas regionais em razão da modernização capitalista, da qual o romance é em si um produto -, uma noção tal suscita discussões sobre sua atualidade. Mesmo no que diz respeito aos aspectos literários, a ideia de um regionalismo modernista parece se ajustar pouco aos romances de um autor como José María Arguedas, a quem a tensão entre narrativa moderna e cultura local se apresenta em grau de irreconciliação.

Nesse sentido, o presente artigo se propõe a um esforço crítico de revisão, não para descartar a contribuição de "Literatura e Subdesenvolvimento", mas para compreender o seu sentido histórico e político a fim de refletir com a devida distância sobre os impasses que o tempo lhe impôs.

\footnotetext{
${ }^{2}$ Candido reclamaria da tradução em carta a Rama: "O artigo já saiu antes do livro, retraduzido pessimamente do espanhol, na revista de história da UNESCO" (CANDIDO, 2018, p. 62).
} 


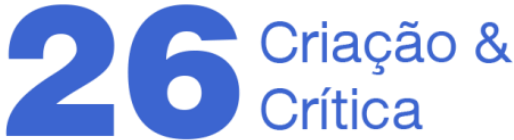

\section{Local e universal}

Para compreender o fio argumentativo de "Literatura e Subdesenvolvimento" é necessário recordar alguns aspectos da obra candidiana máxima, Formação da Literatura Brasileira de 1959. Nesta, o crítico formula de modo cristalino a consigna que pautará praticamente todas suas reflexões ulteriores: "estudar a formação da literatura brasileira como síntese de tendências particularistas e universalistas" (CANDIDO, 2013, p. 25). Tal ideia, de fato, dá a tônica na análise de todos os "momentos decisivos" (CANDIDO, 2013) d'A Formação, desde a versificação da paisagem mineira com métrica e espírito árcades nos poetas inconfidentes, até o romantismo indianista na lírica de Gonçalves Dias ou no romance alencariano.

Para Candido, ainda, um requisito básico para o funcionamento de tal literatura formada, com características locais e universais, seria a existência de um "sistema literário" (CANDIDO, 2013, p. 26) - o conhecido pressuposto sociológico de uma tríade escritorobra-público, onde a poesia e a prosa pudessem circular, constituindo um complexo cultural mais ou menos estável. Daí o crítico, n’A Formação, dedicar páginas ao surgimento das primeiras academias e grêmios, bem como à criação das primeiras Escolas Superiores no período joanino e à (incipiente) ampliação do ensino no Segundo Reinado.

Pois em "Literatura e Subdesenvolvimento", essa dialética literária entre o telúrico e o cosmopolita, operando sociologicamente, reaparecerá. Agora, porém, em outra chave, sobretudo porque visando objetos de estudo diferentes. Dessa vez, de maneira bastante panorâmica e ensaística, Candido ampliará seu olhar para todo o continente latinoamericano. No mesmo sentido, estenderá seu alcance temporal para discutir objetos cronologicamente tão distintos quanto a poesia dos românticos, o romance machadiano, os contos de Jorge Luis Borges, a novela de la tierra, o regionalismo brasileiro e, por fim, o interesse principal do ensaio, o romance latino-americano dos anos 1950 e 1960.

Fundamentalmente, poder-se-ia dizer que a prosa de "Literatura e Subdesenvolvimento" avança do século XIX ao XX analisando as obras também à luz do problema do particular-universal. Assim, primeiramente, observa o ufanismo do romantismo brasileiro na descrição do território, que revelaria uma "noção de país novo" isto é, uma ânsia por estilizar as paisagens da recém fundada pátria, com sentimento romântico importado, mediante exuberâncias adjetivas no tocante à fauna e à flora. Embora Candido não deplore essa tendência, enfatizará seu localismo, usando termos de caráter levemente pejorativo, como "deslumbramento", "exaltação nativista" (CANDIDO, 2011b, p. 169), entre outros.

Em seguida, então, o crítico elogiará a busca de escritores urbanos como Machado de Assis e Jorge Luis Borges por formas mais elaboradas, em detrimento do particular local. Em "Literatura e Subdesenvolvimento", Borges surge, graças a seu presumido "modo novo de conceber a escrita", como o primeiro caso de autor periférico a influenciar os escritores dos países europeus dos quais os moldes literários costumavam ser trazidos. De forma similar, Machado aparece como um autor original, elogiado por 


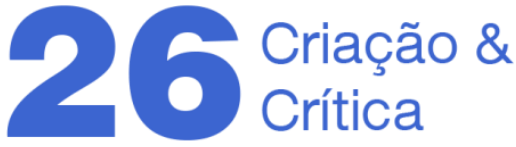

demonstrar a fragilidade do descritivismo e da cor local que teria banido dos seus livros "extraordinariamente requintados" (CANDIDO, 2011b, p. 194).

Aqui, portanto, o elemento local passa a segundo plano, cedendo lugar à técnica. Em detrimento do pitoresco, Candido se concentra na meta-narrativa em abismo de Borges e no narrador "elíptico" e "fragmentário" (CANDIDO, 2011a, p. 22) de Machado. As prosas borgiana e machadiana seriam novos momentos-chave da formação literária: dotadas de inédita universalidade e "requinte", poderiam até mesmo exercer papéis norteadores no concerto internacional das formas.

De modo bastante entusiasmado, Candido apontará ainda o desenvolvimento dessa tendência na narrativa latino-americana dos anos 1960. Seu exemplo modelar é o romance La Ciudad y los Perros (1963), de Mario Vargas Llosa, com seu narrador em primeira pessoa cuja identidade no enredo é oculta até os últimos capítulos, nos quais a revelação (de que se trata do personagem Jaguar) dá nova perspectiva a toda a trama. Palavras de Candido:

Esta técnica parece uma concretização da imagem que Proust usa para sugerir a sua (...); mas significa algo muito diverso, num plano diverso de realidade. Aí, o romancista do país subdesenvolvido recebeu ingredientes que lhe vêm por empréstimo cultural dos países de que costumamos receber as fórmulas literárias. Mas ajustou-as em profundidade ao seu desígnio, para representar problemas do seu próprio país, compondo uma fórmula peculiar: Não há imitação nem reprodução mecânica. Há participação nos recursos que se tornaram bem comum através do estado de dependência, contribuindo para fazer deste uma interdependência (CANDIDO, 2011b, p. 187).

Esse parágrafo em particular representa um salto no argumento de "Literatura e Subdesenvolvimento": considerando a narrativa em seu sentido imanente, passa-se a atribuir significado político à análise formal. Moderna e original, a obra de Vargas Llosa representaria um novo estágio em um almejado processo de emancipação cultural do mundo "subdesenvolvido", na medida em que superaria a dependência estética. Essa libertação, note-se, viria através da própria deglutição da cultura importada, como sugere a ideia de um "empréstimo cultural" que o romancista teria sabido "ajustar a seus desígnios" provincianos.

Por outro lado, em se tratando do século XX, Candido não deixará de apontar a existência de outras vertentes latino-americanas com menor pretensão de universalidade e mais preocupadas com o aspecto representacional da vida no continente. Tal o caso do regionalismo. Vale fazer justiça e notar que, nesse âmbito, a posição do crítico recusa dualismos simplistas. Embora negue valor à novela de la tierra, depreciando o centaurismo de seus vaqueiros e gauchos, Candido exalta escritores localistas mais sóbrios. Diz, por exemplo, que uma obra como Vidas Secas (1938), de Graciliano Ramos, abandona o cavalheirismo e configura objeto de "alta expressão" (CANDIDDO, 2011b, p. 192), operando a passagem da "consciência de país novo" que marcava o romantismo 


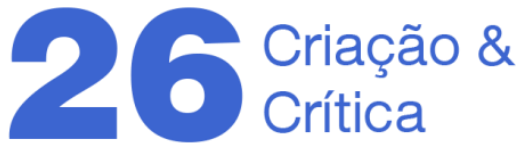

para a "consciência do subdesenvolvimento", denunciando nossas "técnicas arcaicas", nossa "miséria pasmosa" e nossa "incultura paralisante" (CANDIDO, 2011b, p. 171).

Em todos esses momentos, evidencia-se a postura modernizadora subjacente a "Literatura e Subdesenvolvimento": por um lado, seu esquema valoriza o progresso técnico da narrativa como sinônimo de avanço cultural, na medida em que coloca a América Latina dos anos 1960 em posição de competição igual com o centro da modernidade (a Europa); por outro lado, valoriza a ficção que tematiza o atraso socioeconômico, na medida em que esta denuncia a realidade defasada (em relação à Europa) e pressiona politicamente no sentido da modernização. Grosso modo, balizado pelo capitalismo central, o esquema pressupunha uma literatura avançada em uma sociedade por avançar: uma teleologia de literatura e sociedade, cujo ponto de chegada seria a formação da cultura nacional nos moldes dos países ocidentais de capitalismo "desenvolvido".

É assim que, enxergando méritos progressistas em duas vertentes romanescas bastante diversas, Candido apontará um caminho de síntese das mesmas: o "superregionalismo".

\section{O superregionalismo}

Candido começou a lapidar a ideia de uma narrativa super-regional antes mesmo de "Literatura e Subdesenvolvimento", em um artigo sobre Guimarães Rosa escrito em 1970 para a Revista Iberoamericana de Literatura, também a pedido de Ángel Rama. Em tal texto, admitia-se que Grande sertão: veredas pertencia ao gênero regionalista, habitual nas literaturas latino-americanas, que "ainda não puderam superar a apresentação pitoresca da realidade". Contudo, sugeria-se que o seu significado é mais amplo, pois dramatiza aspectos que "formam a textura da alma de todos os homens" com "prolongamentos para uma esfera super-real" (CANDIDO, 1970, p. 61).

No mesmo ano de 1970, a ideia se repetiria em "Literatura e Subdesenvolvimento". Diria Candido:

A realidade econômica do subdesenvolvimento mantém a dimensão regional como objeto vivo, a despeito da dimensão urbana ser cada vez mais atuante. Basta lembrar que alguns dentre os melhores encontram nela substância para livros universalmente significativos, como José María Arguedas, Gabriel García Márquez, Augusto Roa Bastos, João Guimarães Rosa (CANDIDO, 2011b, p. 192).

$\mathrm{Na}$ lógica da historiografia literária da Formação, portanto, tais autores se localizariam em pontos culminantes, na medida em que equilibrariam o alto manejo da técnica a uma "consciência dilacerada do subdesenvolvimento", que "opera uma explosão do tipo de naturalismo que se baseia na referência a uma visão empírica do mundo" (CANDIDO, 2011b, p. 195). A "explosão" em questão, obviamente, se refere aos indiretos- 


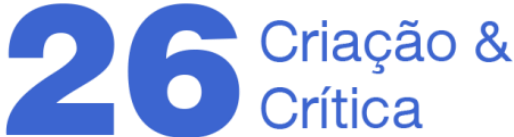

livres, monólogos, fluxos de consciência e visões simultâneas dos escritores mencionados. Com tais técnicas avançadas, pensava Candido, o ângulo crítico do regionalismo tout court, que observava o atraso desde um ponto de vista externo, adquiriria dimensão psicológica e mais profunda - por assim dizer, universal.

$\mathrm{Na}$ teoria literária de língua hispânica, esse modelo encontraria uma versão análoga - e mais influente em nível mundial - no clássico texto de Ángel Rama, "Los Procesos de Transculturación en la Narrativa Latinoamericana" (1974). Grosso modo, tratar-se-ia de descrever o processo através do qual uma cultura recessiva (a matéria regional ou folclórica) produz sínteses ao entrar em contato com elementos da cultura moderna (por exemplo, o romance). Os exemplos do intelectual uruguaio eram quase os mesmos de "Literatura e Subdesenvolvimento"; a saber: "José María Arguedas (19111969), Juan Rulfo (1918), João Guimarães Rosa (1908-1968), Gabriel García Márquez $(1928)^{3 "}$ (RAMA, 2001a, p. 233). Na verdade, a afinidade entre Candido e Rama - aliás celebrada por ambos - era tal que os críticos chegariam a organizar eventos juntos nos quais dariam divulgação a tais ideias. Em uma carta para seu amigo brasileiro, Rama diria:

Inteiramente de acordo com a tese que conduz você progressivamente da mudança, por volta dos anos 30 , do país novo ao país subdesenvolvido e a uma avaliação que resgata o regionalismo em uma perspectiva que você chama de super-regionalismo. É isso mesmo o que the propunha, sob o título de os transculturadores da narrativa, como um dos temas do seminário em minha visita a São Paulo, de tal modo que é seu artigo que pode servir de base para o debate, sem que eu acrescente mais nada" (RAMA, 2018, p. 79).

Dado o prestígio de Candido e Rama, tais ideias se tornariam verdadeiramente modelares para os departamentos onde os amigos intelectuais atuavam. Particularmente nas universidades de São Paulo e Montevidéu, o modelo transculturador-superregionalista funcionaria como nexo explicativo e orientador da historiografia, formando gerações de professores e críticos.

A influência é compreensível: a despeito do que se possa dizer hoje, vale notar que o modelo representava verdadeira lufada de ar fresco para a crítica dos anos 1970. À época, o que caracterizava o debate literário latino-americano era ainda a polêmica bizantina entre "modernismo" e "realismo" que preocupara a Europa na primeira metade do século. Vide, a propósito, os críticos que Candido menciona em seu ensaio: por um lado, o venezuelano Manuel Pedro González, famoso por deplorar os romances de Vargas Llosa e rechaçar as técnicas do romance do Primeiro Mundo; ${ }^{4}$ por outro lado, o uruguaio Rodríguez Monegal, cuja publicação Mundo Nuevo, financiada pelo "Congress for Cultural Freedom" (organismo cultural da Agência de Inteligência Americana),

\footnotetext{
${ }^{3}$ Rama já havia evocado os mesmos autores no texto "Meio Século de Narrativa Latino-Americana (1922-1972)" (1973), chamando-os de "aculturadores narrativos" (RAMA, 2001b, p. 190).

${ }^{4}$ González condena o deslumbramento, por parte do escritor latino-americano, em relação às "técnicas marginais e as piruetas de estilo e pontuação que Paris e Nova York exportam" (GONZÁLEZ, 1967, p. 36).
} 


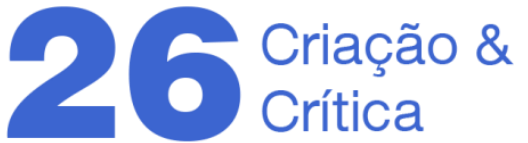

combatia enfaticamente o regionalismo e exaltava o experimentalismo estético ${ }^{5}$, sugerindo, nas palavras de Idelber Avelar, uma modernização literária "de direita" (AVELAR, 2003, p. 40). Nesse universo crítico bipolar, característico da situação periférica em meio à Guerra Fria, Candido e Rama tiveram o indiscutível mérito histórico de oferecer uma terceira via.

Olhada com a devida distância histórica e crítica, porém, isso não significa que o esquema super-regional (ou transculturador) fosse desprovido de pontos delicados, como veremos a seguir.

\section{Desenvolvimentismo e estratégia social}

Como na Formação da Literatura Brasileira, Candido se preocupava em dar lastro material ao processo literário universalista que identificava nos anos 1960, procurando modos de reforçar um sistema continental onde as obras "super-regionais" pudessem adquirir organicidade. O desafio, agora, seria ainda maior, dada a existência de um inimigo ainda não identificado nas teorias de formação: "a cultura de massa" (CANDIDO, 2011b, p. 174). Distinguindo claramente essa última da "fase folclórica" da cultura popular, associada às regiões não-citadinas, Candido nota o despontar de uma "espécie de folclore urbano" largamente difundido por meio do rádio, da televisão e da história em quadrinhos. O problema anunciado seria de duas ordens: sem o intermédio da educação e da instrução, tais artefatos de comunicação modernos poderiam atirar diretamente os alfabetizados junto com os letrados na cultura universalista industrialmente produzida. Além disso, detendo o monopólio do know-how dos próprios materiais já elaborados de cultura massificada, os países imperialistas poderiam "não apenas difundir normalmente os seus valores, mas atuar anormalmente através deles para orientar a opinião e a

\footnotetext{
${ }^{5}$ A respeito de revistas como Mundo Nuevo, diz a crítica Jean Franco: "O apelo aos latinoamericanos por organizações de frente, como o Congress for Cultural Freedom, não era apenas liberdade mas inclusão na cultura 'universal', embora isso disfarçasse um ataque não tão sutil a culturas nacionais, étnicas e locais, que foram depreciadas como aberrantes, meramente provincianas ou idiossincráticas. Isso deu ao projeto uma intenção mais frontalmente declarada do que os modernismos estéticos de Europa e Estados Unidos, cujo poder, nas palavras de Fredric Jameson, 'foi, durante a Guerra Fria e no período de sua canonização norte-americana, deslocado e investido em formas essencialmente anti-políticas de esteticismo acadêmico'". Tradução própria de: "The appeal to Latin Americans dangled by front organizations, such as the Congress for Cultural Freedom, was not only freedom but inclusion in 'universal' culture, although this disguised a not-sosubtle attack on national, ethnic, and local cultures, which were denigrated as aberrant, as merely provincial, or as idiosyncratic. This gave the project a rather more frontally avowed intention than the aesthetic modernisms of Europe and the United States, the power of which, in Fredric Jameson's words, 'was, during the cold war and in the period of their North American canonization, displaced and invested in essentially anti-political forms of academic aestheticism"' (FRANCO, 2002, p. 2).
} 


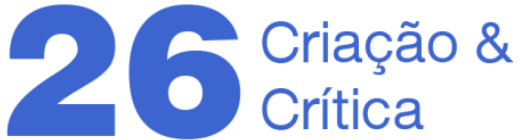

sensibilidade das populações subdesenvolvidas no sentido dos seus interesses políticos" (CANDIDO, 2011b, p. 175) ${ }^{6}$.

Daí que o crítico enfatizasse também a necessidade de uma constante luta pedagógica e anti-imperialista, com vistas a fazer frente a essa ameaça. É característica sua denúncia das nossas "políticas educacionais ineptas ou criminosamente desinteressadas" (CANDIDO, 2011b, p. 172) como óbices à criação de uma verdadeira cultura literária. Seria preciso empreender urgentemente um esforço no sentido da politização e do avanço material e cultural a fim de acompanhar e sustentar o melhoramento literário que parecia já acontecer. Em outras palavras: lutar para dar às populações locais as condições de apreciar o romance transculturador ao invés da cultura de massa.

Essa "vontade de combate" (CANDIDO, 2011b, p. 171) - como diz Candido respirava ares bastante peculiares quando da publicação de "Literatura e Subdesenvolvimento". Como se sabe, a década de 1960 foi o período dourado do desenvolvimentismo na América Latina. Ideologia tal acompanhava as agendas modernizadoras dos governos do Partido Revolucionário Institucional no México, de Perón e Frondizi, na Argentina e de Vargas e Kubitschek, no Brasil. Amparados em alianças de classes, os governos desenvolvimentistas locais eram ainda alimentados pelas diretrizes da famosa Comissão Econômica para a América Latina e o Caribe, a CEPAL - think tank da Organização das Nações Unidas dirigido pelo argentino Raúl Prebisch, que preconizava políticas industrializantes. Por todo o continente, a intelligentsia buscava modos de conquistar autonomia em relação ao capital estrangeiro.

Em "Literatura e Subdesenvolvimento", mais de uma vez, fica evidente o entusiasmo com esse cenário. O próprio título do texto revela sua filiação ao programa cepalino, cujas publicações traziam quase todas a categoria de "desenvolvimento" em seus nomes". Não obstante, Candido refere-se a uma "tomada de consciência dos economistas e políticos" (CANDIDO, 2011b, p. 172) e enxerga na "ideia de subdesenvolvimento uma força propulsora, que dá novo cunho ao tradicional empenho político dos nossos intelectuais" (CANDIDO, 2011b, p. 171). A alusão à CEPAL - onde trabalhavam seus colegas e amigos pessoais Celso Furtado e Fernando Henrique Cardoso - é bastante clara.

\footnotetext{
${ }^{6}$ Candido usa alguns exemplos que, em face do repertório contemporâneo, parecem remotos: "É normal, por exemplo, que a imagem do herói de far-west se difunda, porque, independente dos juízos de valor, é um dos traços da cultura norte-americana incorporado à sensibilidade média do mundo contemporâneo. Em países de larga imigração japonesa, como o Peru e sobretudo o Brasil, está-se difundindo de maneira também normal a imagem do samurai, sobretudo por meio do cinema. Mas é anormal que tais imagens sirvam de veículo para inculcar nos públicos dos países subdesenvolvidos atitudes e ideias que os identifiquem aos interesses políticos e econômicos dos países onde foram elaboradas" (CANDIDO, 2011b, p. 175).

7 Vide a revista Desarrollo Económico da CEPAL, onde Prebisch publicaria El Desarrollo Económico de la América Latina y Algunos de sus Principales Problemas (1949), ou a clássica obra Dependência e Desenvolvimento na América Latina: Ensaio de Interpretação Sociológica (1969), de Fernando Henrique Cardoso e Enzo Faletto.
} 


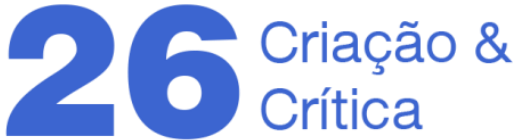

A óbvia pedra no meio desse caminho emancipatório eram as Ditaduras Militares, que, àquela altura, já se haviam estabelecido em Brasil, Argentina, Peru e Guatemala. Supondo (ainda sem a clareza dos anos seguintes) que estas seriam pró-imperialistas, Candido demonstrava bastante consciência do problema colocado ao afirmar que éramos "um continente sob intervenção" (CANDIDO, 2011b, p. 176). Por isso, inclusive, não descartava a necessidade de soluções radicais. Seu elogio de Cuba como "admirável vanguarda da América na luta contra o subdesenvolvimento e seus fatores" (CANDIDO, 2011 b, p. 188) revelava tanto voluntarismo quanto coragem em um momento em que 0 Al-5 já operava e a luta armada brasileira dava seus primeiros passos.

Em todo caso, os próximos capítulos dessa história são conhecidos. As vias radicais da esquerda foram fechadas a sangue. Nem a emancipação continental, nem o progresso material ou educacional aconteceram. Na ressaca do desenvolvimento híbrido dos anos Geisel, que aumentara a desigualdade e a dependência ao invés de diminuí-las, Roberto Schwarz, em 1986, se perguntava: "como seria a cultura popular se fosse possível preservá-la do comércio e, sobretudo, da comunicação de massa? O que seria uma economia nacional sem mistura?". O próprio crítico respondia: "De 64 para cá, a internacionalização do capital, a mercantilização das relações sociais e a presença da mídia avançaram tanto que estas questões perderam a verossimilhança" (SCHWARZ, 2012, p. 32).

Em outras palavras: se o problema, para Candido, era abrir as vias para o desenvolvimento, este findou por ser tocado à direita, em detrimento das culturas regionais, da democracia e da igualdade social. Mutadis mutandis, seria importante refletir sobre a atualidade de "Literatura e Subdesenvolvimento": se sua aposta na formação continental a espelhar a formação literária foi desqualificada pelo rumo dos acontecimentos, seria a teoria do super-regionalismo - ou seu correlato transculturador ainda válida para lidar com as questões literárias de então? Ou, mais do que isso: não seria a ideologia desenvolvimentista, subjacente ao conceito do super-regional, pouco sensível a eventuais efeitos indesejáveis da modernização?

Responder essas perguntas requer atentar para formulações do texto que resultam perigosamente ambíguas. Por exemplo: entendido o chamado "folclore" - isto é, as culturas ou reminiscências culturais locais, não-modernas - como uma "fase", o lugar reservado a esse fica pouco claro em "Literatura e Subdesenvolvimento". Devemos nos questionar: mesmo que o projeto político do texto triunfasse e os efeitos deletérios do "folclore urbano" transmitido pelos mass media fossem contidos pelo ensino formal, o que seria da "fase" das culturas não-citadinas em uma nova era de desenvolvimento progressista? Ainda que incorporadas pelo romance super-regionalista, elas, ipso facto, teriam o direito de existir de outra maneira?

É preciso reconhecer que, na conceituação candidiana do super-regionalismo, segundo a qual "o subdesenvolvimento mantém o elemento regional vivo", a questão fica irresolvida. Na formulação, pois, está implícita a ideia de que o desenvolvimento (isto é, o alvo fundamental do projeto desenvolvimentista que permeia o texto) tornaria os traços particulares locais desprovidos de sentido. Daí, talvez, o vislumbre de um futuro onde 


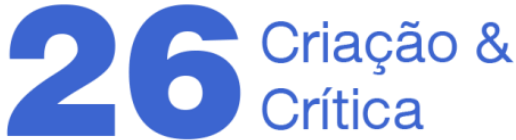

"Não se exigirá mais (...) que Cortázar cante a vida de Juan Moreyra, ou Clarice Lispector explore o vocabulário sertanejo" (CANDIDO, 2011b, p. 196)": os escritores urbanos teriam vencido a etapa do atavismo regional que os romances pitorescos ou super-regionais "ainda não conseguiram superar". Ora, porém, foi justamente o desenvolvimento capitalista realmente ocorrido, promovido pelas ditaduras militares, que apagou as diferentes culturas regionais através do etnocídio industrializante. Nesse sentido, olhado o processo histórico, a categoria de "super-regionalismo", associada a um projeto de modernização, carregaria mais uma carga de tensão do que de equilíbrio, já que buscava conciliar dois elementos - o local e o universal - historicamente destinados a se oporem.

Isso, claro, não significa dizer que o projeto desenvolvimentista de Candido fosse o mesmo de Costa e Silva ou Médici. Ao contrário, "Literatura e Subdesenvolvimento" representa uma disputa com os generais brasileiros (e com os governos latinoamericanos em geral) em relação aos rumos do "desenvolvimento". De qualquer forma, considerado o desfecho da luta, pode-se pensar se a ideia de um secularismo - uma literatura universalista - que incorporasse sinteticamente 0 particular local não representou, ao invés de uma saída para as culturas locais, uma mera etapa em um longo processo de apagamento.

\section{O caso Arguedas}

Com efeito, a obra de um autor em particular dentre os apontados por Candido como exemplos super-regionais parece ter captado esse problema antes mesmo da publicação de "Literatura e Subdesenvolvimento". Trata-se de José María Arguedas.

A biografia do autor não apenas contribuiu com seus diagnósticos como se tornou parte constituinte de sua obra. Embora filho de uma família de classe média criolla, Arguedas nasceu na região andina do Peru e, desde cedo, teve intenso contato com a cultura quéchua, aprendendo a falar seu idioma com fluência. Tendo estudado na Universidad de San Marcos, doutorou-se em etnologia e aprofundou seu conhecimento das populações autóctones peruanas, realizando trabalhos notáveis nesse âmbito, como a compilação de lendas indígenas Dioses y hombres de Huarochiri (1966).

Como escritor de ficção, Arguedas sempre foi figura conflituosa no interior do quadro literário sessentista. Uma das razões para tal, aliás, era sua relutância em aceitar a ideia de um programa narrativo universalizante que, a seu ver, era a tônica do período. Antes de se suicidar, em 1969, por exemplo, o escritor diria em um de seus diários:

(...) ese Carlos Fuentes no entendería bien. Perdónenme los amigos de Fuentes, entre ellos Mario Vargas Llosa y este Cortázar que aguijonea con su "genialidad", con sus solemnes convicciones de que mejor se entiende la esencia de lo nacional desde las altas esferas de lo supranacional. Como si yo, criado entre la gente de don Felipe Maywa, metido en el oqllo mismo de los indios durante algunos años de la infancia para luego volver a la esfera "supra-india" de donde había "descendido" entre los quechuas, 


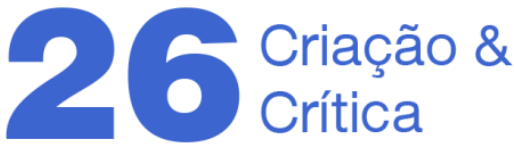

dijera que mejor, mucho más esencialmente interpreto el espíritu, el apetito de don Felipe, que el propio don Felipe. ¡Falta de respeto y legítima consideración! No se justifica (ARGUEDAS, 2006, p. 24-25).

Curiosamente, a crítica de Arguedas a Cortázar, aqui, se refere às opiniões defendidas pelo escritor argentino em uma entrevista à revista Life, no ano de 1969 entrevista, aliás, que Candido elogia por trazer "coisas interessantes sobre o novo aspecto que apresentam fidelidade local e mobilidade mundial" (CANDIDO, 2011b, p. 187). Isto é, certamente o peruano se sentiria pouco confortável em ter sua obra classificada como "super-regionalista". O sarcasmo com que se refere às "altas esferas de lo supranacional" parece deixar pouca dúvida a esse respeito.

Candido, evidentemente, não teve conhecimento da questão ao redigir "Literatura e Subdesenvolvimento", sobretudo porque os diários de Arguedas seriam apenas publicados postumamente, em 1973, como parte do (também póstumo) romance El Zorro de Arriba y el Zorro de Abajo. Em todo caso, seria possível, antes disso, observar pontos de tensão na obra do peruano no que diz respeito à ideia de uma literatura que conciliasse os expedientes narrativos modernos (e/ou modernistas) à matéria cultural quéchua.

Por exemplo: no romance Los Ríos Profundos, de 1958, Arguedas narra a história do jovem Ernesto, que é matriculado por seu pai em um colégio religioso na cidade de Abancay, região montanhosa do Peru. Cindido entre a cosmovisão ocidental da elite criolla e a das populações indígenas exploradas, o personagem vive em permanente estado de conflito. Desde o princípio, rechaça o modo de vida dos brancos proprietários de terra amigos de sua família. O próprio narrador, em primeira pessoa, descreve o catolicismo e a escola cristã com tintas brutais. Os padres responsáveis pela instituição onde Ernesto se vê confinado são autoritários com as crianças e demonstram total incompreensão da diversidade cultural peruana, a qual em verdade combatem a bem da evangelização.

Com fortes acentos autobiográficos, a obra tem pouca (ou nenhuma) pretensão de mobilizar as técnicas da última hora. Em verdade, o que dá seu acento fragmentário é menos um modernismo consistente do que a montagem algo artesanal da história fictícia aliás contada de maneira bastante convencional - com as descrições de paisagens, animais e objetos da cultura quéchua nas quais transparece a veia etnológica do autor. Trata-se efetivamente de uma dicotomia estrutural: toda a história inserida no universo ocidental - isto é, a parte de Los Ríos Profundos passada no colégio religioso - é retratada a modo de opressão violenta, ao passo que as passagens ligadas aos costumes locais surgem como momentos de libertação lírica. Vejamos, a título de exemplo, o caso de dois objetos da(s) cultura(s) evocados pelo romance: a catedral católica construída em Cuzco pelos colonizadores e o brinquedo indígena Zumbayllu, começando pela primeira:

Era una inmensa fachada; parecía ser tan ancha como la base de las montañas que se elevan desde las orillas de algunos lagos de altura. En el silencio, las torres y el atrio repetían la menor resonancia, igual que las montañas de roca que orillan los lagos helados. La roca devuelve profundamente el grito de los patos o la voz humana. Ese eco es difuso y 


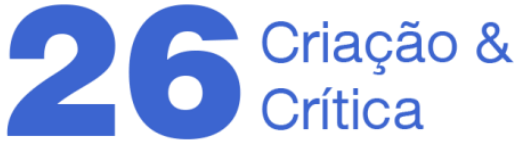

parece que naciera del propio pecho del viajero, atento, oprimido por el silencio. (p. 48)

Agora, como Arguedas trata da descoberta do zumbayllu:

¿Qué podía ser el zumbayllu? ¿Qué podía nombrar esta palabra cuya terminación me recordaba bellos y misteriosos objetos? El humilde Palacios había corrido casi encabezando todo el grupo de muchachos que fueron a ver el zumbayllu; había dado un gran salto para llegar primero al campo de recreo. Y estaba allí, mirando las manos de Antero. Una gran dicha, anhelante, daba a su rostro el esplendor que no tenía antes (ARGUEDAS, 2006, p. 117-118).

A igreja é silenciosa e opressiva; o brinquedo desperta fascínio. O contraste é explícito. Mais do que que isso: configura uma oposição irreconciliável, com tomada de partido por um dos lados (no caso, o indígena).

Além dessa peculiaridade formal, como observa Marcos Natali, Los Ríos Profundos apresenta ainda um forte grau de "tensão do processo de produção linguística" (2005). Há uma passagem, por exemplo, em que o narrador Ernesto é solicitado por um amigo a escrever uma carta romântica. O personagem é então tomado por um súbito sentimento "de aguda verguenza" (ARGUEDAS, 2006, p. 126), passando a se perguntar como redigiria uma carta parecida às jovens indígenas de seu país. A língua autóctone, na tessitura textual, irrompe aí de maneira abrupta, sem conciliação transcultural possível em relação ao castelhano: "escribí: Uyariy chay k'atik'niki siwar k'entita" (ARGUEDAS, 2006, p. 126).

Esse conflito entre o particular e o cosmopolita, expresso, como vimos, em todos os níveis da narrativa, segue até o desfecho, quando o narrador Ernesto abandona a vida no internato para aderir à luta do povo indígena contra seus exploradores urbanos. $O$ fato de que as populações autóctones sejam afligidas por uma peste trazida pela urbanização não o impede de, reconciliado, exclamar feliz: "YYa no voy a regressar nunca!" (ARGUEDAS, 2006, p. 306). Isto é, a epifania se dá, simultaneamente, por adesão a um modo de vida não-moderno e por recusa da modernidade.

Em outras palavras, se parte dos escritores latino-americanos dos anos 1960 buscavam uma forma narrativa universal, Arguedas descobrira um narrador altero, que rejeita a urbanidade ocidental posta e se desafoga nas passagens poéticas em que (re)descobre a vida e a natureza intocadas pelo colonizador. Uma forma que não deixava de ser moderna (pois se tratava, apesar de tudo, de um romance), mas com dilemas e sugestões bem distintas daquelas que Candido exaltara em seu ensaio (pois já não se tratava mais de reinterpretar as técnicas universais do modernismo europeu).

Lida desse modo, a narrativa genuinamente "localista" de Arguedas parece de fato ter pouco ou nada que ver com o cosmopolitismo "super-regional" que o crítico enxerga em vários escritores dos anos 1960. Em Los Ríos Profundos, afinal, não se tinha o equilíbrio harmonioso entre o local e o universal, mas sim o conflito linguístico aberto e a

\footnotetext{
${ }^{8}$ Trata-se do verso de uma canção quéchua, cuja tradução (livre) ao português seria: "escute o beija-flor esmeralda que te segue. Ele te falará de mim".
} 


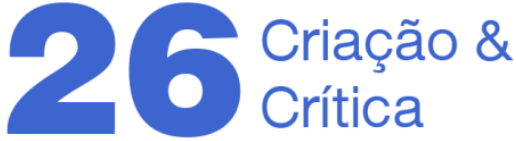

tensão permanente em relação à forma romanesca, constantemente vazada por relatos de antropologia e pela subjetividade do próprio autor, consciente de que o avanço da cultura ocidental representaria a extinção dos costumes que amava.

Candido poderia ter caminhado por uma leitura similar da obra de Arguedas em "Literatura e Subdesenvolvimento", mas não o fez em função de um esquema literário a espelhar a aposta política no desenvolvimento das nações. Nesse quadro, reservou-se ao escritor peruano um posto mais "universal" do que o próprio certamente gostaria - o que faz pouca justiça a uma leitura atenta de Los Ríos Profundos. Considerando o processo histórico em retrospectiva, bem como as contribuições mais recentes da crítica, seria impossível não apontar esse ponto cego do modelo candidiano.

\section{Super-regionalismo ou hibridismo?}

Do ponto de vista dos problemas aqui enunciados, é fato que a teoria da transculturação de Ángel Rama passou por retificações no âmbito da teoria literária de língua hispânica - o que nem tanto vale para a teoria do super-regionalismo candidiano no Brasil. Em 1997, por exemplo, tornar-se-ia conhecida a polêmica levantada pelo crítico peruano Antonio Cornejo Polar - aliás, leitor de Arguedas -, para quem o modelo transculturador parecia excessivamente conciliatório. Diria o próprio:

pese a mi irrestricto respeto por Ángel Rama - la idea de transculturación se ha convertido cada vez más en la cobertura más sofisticada de la categoría de mestizaje. Después de todo el símbolo del 'ajiaco' de Fernando Ortiz que reasume Rama bien puede ser el emblema mayor de la falaz armonía en la que habría concluido un proceso multiple de mixturación. Aclaro que en modo alguno desconozco las obvias o subterráneas relaciones que se dan entre los diversos estratos socioculturales de América Latina; lo que objeto es la interpretación según la cual todo habría quedado armonizado dentro de espacios espacibles y amenos (y por cierto hechizos), de nuestra América (POLAR, 1997, p. 341-342).

A partir dessa formulação, Cornejo Polar sugere a ideia de "hibridez" como forma de compreender os conflitos culturais internos aos romances de muitos escritores dos anos 1960, entre os quais Arguedas. Trata-se, fundamentalmente, de explorar as contradições e dissonâncias constituintes das formas literárias em seu conflito latinoamericano entre o particular (a cultura local) e o universal (a modernização literária).

Se vale para a noção de transculturação, a ideia de um hibridismo conflituoso pode atualizar o modelo sugerido por Candido em "Literatura e Subdesenvolvimento", permitindo entender as obras de alguns de seus autores estudados (bem pesado caso a caso) na chave de uma tensão maior que, afinal, seguiria sangrentamente viva no processo histórico. Isso, quem sabe, permitiria resgatar alguns desses romances em chave crítica, não nos termos de emulações de um desenvolvimento a cumprir, mas como antevisões dos conflitos inerentes à modernização periférica. Talvez a categoria de 


\section{$26^{\text {cratacio } 8}$}

"consciência dilacerada", em Antonio Candido, já sugerisse algo assim. Caberia à crítica contemporânea explorar melhor a questão e desenvolvê-la.

\section{Referências}

ARGUEDAS, José María. El Zorro de Arriba y el Zorro de Abajo (1973). Caracas: Fundación Editorial El Perro y la Rana, 2006. Los Ríos Profundos (1958). Caracas: Fundación Editorial El Perro y la Rana, 2006.

AVELAR, Idelber. The Untimely Present: Postdictatorial Latin-American Fiction and the Task of Mourning (1999) / Alegoria da Derrota: a Ficção Pós-Ditatorial e o Trabalho do Luto na América Latina. Tradução: Saulo Gouveia. Belo Horizonte: Editora UFMG, 2003.

CANDIDO, Antonio. "Carta a Ángel Rama" (1971). Em: ROCCA, Pablo (Org.). Conversa Cortada - A Correspondência Entre Antonio Candido e Ángel Rama: o Esboço de um Projeto Latino-Americano, 1960-1983. Tradução dos textos em espanhol: Ernani Só. São Paulo/ Rio de Janeiro: EDUSP e Ouro Sobre Azul, 2018.

. "Esquema de Machado de Assis" (1968). Em: Vários Escritos. 5ª Edição. Rio de Janeiro: Ouro Sobre Azul, 2011a. "Literatura e Subdesenvolvimento" (1970). Em: A Educação Pela Noite. 6” Edição. Rio de Janeiro: Ouro Sobre Azul, 2011b.

Edição. Rio de Janeiro: Ouro Sobre Azul, 2013. Formação da Literatura Brasileira - Momentos Decisivos (1959). 14ª "Ser Jagunço em Guimarães Rosa". Em: Revista Iberoamericana de Literatura. №2. Montevidéu, 1970.

FRANCO, Jean. The decline \& fall of the Lettered City. Latin America in the Cold War. Cambridge: Harvard University Press, 2002.

GONZÁlEZ, Manuel Pedro. Reparos al Premio Romulo Gallegos. Em: Zona Franca. № 51. Carcacas: Novembro, 1967.

NATALI, Marcos. "José María Arguedas aquém da literatura". Em: Estudos Avançados. Vol. 19, no. 55. São Paulo, 2005.

POLAR, Antonio Cornejo. "Mestizaje e hibridez: los riesgos de las metáforas". Revista Iberoamericana, n. 180, Pittsburgh, University of Pittsburgh, 1997.

RAMA, Ángel. Carta a Antonio Candido (1973). Em: ROCCA, Pablo (Org.). Conversa Cortada - A Correspondência Entre Antonio Candido e Ángel Rama: o Esboço de um Projeto Latino-Americano, 1960-1983. Tradução dos textos em espanhol: Ernani Só. São Paulo/ Rio de Janeiro: EDUSP e Ouro Sobre Azul, 2018.

"Los Procesos de Transculturación en la Narrativa Latino-Americana" (1974) / "Os Processos de Transculturação na Narrativa Latino-Americana". Em: AGUIAR, Flávio e VASCONCELOS, Sandra Guardini. Literatura e Cultura na América Latina. Tradução: Elza Gasparotto e Raquel la Corte dos Santos. 3aㅡ Edição. São Paulo: EDUSP, 2001 a. 


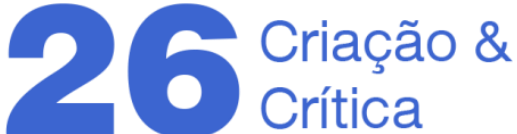

"Medio Siglo de Narrativa Latino-Americana (1922-1972)" (1973) / "Meio

Século de Narrativa Latino-Americana (1922-1972)". Em: AGUIAR, Flávio e VASCONCELOS, Sandra Guardini. Literatura e Cultura na América Latina. Tradução: Elza Gasparotto e Raquel la Corte dos Santos. 3ª Edição. São Paulo: EDUSP, 2001b.

SCHWARZ, Roberto. "Nacional por Subtração" (1986). Em: Que horas são? - Ensaios. 1964-1969. 2a Edição. São Paulo: Companhia das Letras, 2012.

"Antonio Candido". Em: FONSECA, Maria Augusta e SCHWARZ, Roberto (org.). Antonio Candido - 100 Anos. São Paulo: Editora 34, 2018.

Recebido em: 13/12/2019

Aceito em: 19/12/2019

Referência eletrônica: LIMA, Gabriel dos Santos. A teoria desenvolvimentista do "superregionalismo" em Antonio Candido e o caso Arguedas. Criação \& Crítica, n. 26, p., jun. 2020. Disponível em: <http://revistas.usp.br/criacaoecritica>. Acesso em: dd mmm. aaaa. 